\title{
Performance enhancement of hexagonal-patch dual-band array antenna with omega-shaped DGS for dual Band RADAR Applications
}

\author{
Kanchan Wagh* and S. S. Shriramwar \\ Priyadarshini College of Engineering, Nagpur 440 025, India
}

This article presents an antenna array with novelshaped defected ground structure (DGS) incorporated into the ground plane to enhance the bandwidth. It is observed that cross-polarization of the antenna is reduced by inserting omega-shaped DGS into the design. A $4 \times 4$ planar antenna with corporate feed has been designed with and without omega-shaped DGS into the ground plane. Four Omega-shaped DGSs have been placed vertically between the patch elements. These have been placed exactly at the back portion of the microstrip feed line in the ground plane. This antenna array is designed for dual-band applications. It has been observed that the bandwidth of the antenna get enhanced drastically. At $2.4 \mathrm{GHz}$, the bandwidth is $1860 \mathrm{MHz}$ and at $5.8 \mathrm{GHz}$ it is $2500 \mathrm{MHz}$ with DGS. This type of antenna array can be used for WLAN and weather radar systems. The antenna has been designed using CST software.

Keywords: Antenna array, cross-polarization, defected ground structure, performance enhancement, radar.

MICROSTRIP antennas are currently one of the fastest emerging segments in the telecommunication industry and are become a promising medium in the field of communication. These are high-bandwidth, high-gain antennas in the radar systems. The requirements of radar systems are higher bandwidth with lower side lobe level. High-gain antennas are also needed for specific applications. Research has been conducted in the recent past to enhance the performance and efficiency of these patch antennas ${ }^{1}$. Due to their superiority, microstrip antennas are commonly preferred for radar applications. Various techniques are incorporated in the antenna array for enhancement of antenna parameters like gain, bandwidth, and surface wave cancellation. Complimentary Split Ring Resonator (CSRR) has been incorporated into the design. It is the dual counterpart of split ring resonator which manifests band-stop characteristics at resonant frequency if electromagnetic fields are arranged appropriately ${ }^{2}$. Bandwidth improvement achieve by embedding capacitive slits into the design with a truncated ground plane and exciting the antenna through a meandered strip line

*For correspondence. (e-mail: kanchanwagh5@gmail.com) feed $^{3}$. A novel bandwidth enhanced UWB tapered slot antenna with $\mathrm{Y}$-shaped corrugated edges was proposed earlier ${ }^{4}$. High-efficiency antenna array for automotive radar system has been reported ${ }^{5}$. A combination of seriesfed patch antenna arrays and slots has been introduced leading to an antenna array with wide band, low side lobe level and high front-to-back ratio ${ }^{6}$. Feeding techniques play an important role in the antenna array community. Various feeds like corporate feed, centre feed, series feeds are is preferred depending on the antenna application. Centre-fed series array antenna for $\mathrm{K} / \mathrm{Ka}$ band has been designed and fabricated ${ }^{7}$. A 23-elements series-fed linear array designed at $\mathrm{Ka}$ band gives a gain of $19 \mathrm{dBi}$ and SLL better than $-15 \mathrm{~dB}$. Seven-element series-fed antenna array has also been designed and fabricated for high gain ${ }^{8}$. An array of 32 identical square microstrip patches has been designed at $9.35 \mathrm{GHz}$ and $100 \mathrm{MHz}$ bandwidth for marine radar applications ${ }^{9}$. A differential feeding technique for a broadband planar antenna array has been presented ${ }^{10}$. The two antenna beams are realized by exciting the opposite feeds of a dual-fed array antenna ${ }^{11}$.

In the present study, a $4 \times 4$ antenna array is designed at $2.4 \mathrm{GHz}$ and $5.8 \mathrm{GHz}$. Rectangular patch antenna is common, but in this design we have chosen hexagonalshaped patch. In this shape a slot is cut out to introduce an additional resonant frequency of $5.8 \mathrm{GHz}$. By inserting the square open slot into the hexagonal patch, an additional band is introduced. A corporate feeding technique is preferred for this array. Power is equally distributed in the corporate feeding technique. This design gives a good amount of bandwidth for both the frequency bands. At $2.4 \mathrm{GHz}$ the bandwidth is $1100 \mathrm{MHz}$, while at $5.8 \mathrm{GHz}$ it is $2400 \mathrm{MHz}$. Figure 1 shows 16-element array antenna design without defected ground structure (DGS).

\section{Design methodology}

It is observed that when an omega-shaped DGS is incorporated into the ground plane, the bandwidth improves drastically. It is $1860 \mathrm{GHz}$ for $2.4 \mathrm{GHz}$ and $2500 \mathrm{GHz}$ for $5.8 \mathrm{GHz}$ centre frequency. The antenna parameters also improve to a great extent after the inclusion of DGS into the ground plane. Here the basic aim of the DGS is to improve the bandwidth and decrease cross-polarization between the patch elements. A novel omega-shaped DGS 


\section{RESEARCH ARTICLES}

is inserted into the ground plane. In this design four omegashaped DGSs are designed in a vertical fashion into the ground plane. Each DGS is inserted between two patch elements. Due to the effect of the DGS, the current path is also increased, so there will be an increase in bandwidth for both the frequencies. Also, it reduces mutual coupling between the elements. Once mutual coupling is reduced, the antenna parameters will improve. So mutual coupling is the most critical part in array design. A novel structure has been proposed to reduce the mutual coupling between two coplanar microstrip antennas by inserting $\mathrm{H}$-shaped $\mathrm{DGS}^{12}$. Without affecting the radiation behaviour, this antenna reduces mutual coupling between two antennas. DGS is also used to suppress higher-order harmonics ${ }^{13}$. A multiband, dollar-shaped patch antenna array has been designed ${ }^{14}$. Bandwidth of the antenna is also affected by varying the height of the dielectric substrate and width of the patch ${ }^{15}$. The omega-shaped DGS is rotated clockwise by $90^{\circ}$. Results are observed with and without DGS and compared. Bandwidth improves by $760 \mathrm{MHz}$ at $2.4 \mathrm{GHz}$ and $100 \mathrm{MHz}$ at $5.8 \mathrm{GHz}$. Good impedance matching is also observed. Beam width is $30 \mathrm{~dB}$ and side lobe level is $-20.11 \mathrm{~dB}$. Cross-polarization is also reduced and is observed to be $-16.5 \mathrm{~dB}$. The electromagnetic simulation tool CST was used to simulate the
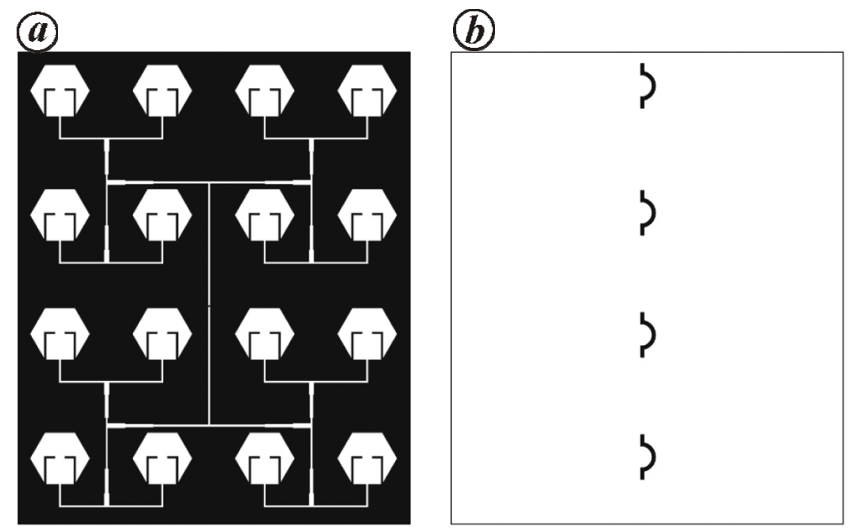

Figure 1. $\boldsymbol{a}, 4 \times 4$ antenna array; $\boldsymbol{b}$, Four omega shaped DGS on ground plane.

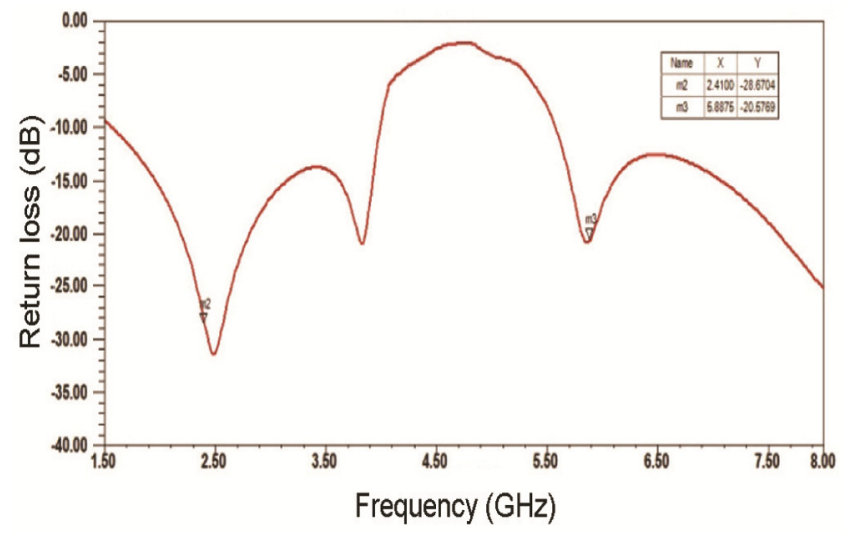

Figure 2. Return loss of antenna array without defected ground structure (DGS). proposed antenna. Figure 2 shows the return loss. Figure $3 a$ and $b$ shows the two dimensional and three dimensional radiation pattern of the antenna array without CSRR. It can be seen that the proposed antenna exhibits good performance in terms of return loss, bandwidth and cross-polarization for dual-band frequency application. Figure 4 shows the omega-shaped DGS which has been incorporated into the ground plane. Figure 5 shows twodimensional radiation pattern of 16-element planar array with DGS incorporated into the ground plane. Figures 68 show the performance plot of the array. Antenna miniaturization has become the most important topic of research in phased array antenna. DGS has been widely used for antenna miniaturization purpose. Work has also been done on gain improvement. In this study, we focus on bandwidth improvement. Some radar systems require higher bandwidth along with dual band, e.g. weather radar system. Further gain can also be improved by using frequency selective surface as mentioned ${ }^{16}$. Initially hexagonal patch antenna is designed at $2.4 \mathrm{GHz}$ (S-band). It is further miniaturized by inserting square broken slots into the design. Hence the second centre frequency is at $5.8 \mathrm{GHz}$. Again, size reduction takes place by the inclusion of an omega-shaped DGS into the design. The vertical length of the DGS is $28 \mathrm{~mm}$ and width is $2 \mathrm{~mm}$. Four omega-shaped DGSs are inserted into the ground plane, each DGS between two patch elements and exactly on the backside of microstrip feed line. The dimensions of the antenna have been optimized using CST software.

The DGS and electromagnetic band gap structure (photonic band gap) are the generic structures mostly used for the design of compact and high-performance microwave components $^{17}$. They are incorporated to reject unwanted frequency and to reduce the size of the antenna. DGS is an etched structure of any shape in the ground plane. Performance of the antenna can be improved by inserting defects into the ground plane ${ }^{18}$. The shape of the DGS can be changed from simple to complicated for improvement of antenna performance. The equivalent circuit of the DGS consists of a series combination of resistance, inductance and capacitance in parallel combination. After insertion of the DGS at the ground plane, it disturbs the current distribution. This affects the transmission characteristics such as line capacitance and inductance ${ }^{19}$. A novel configuration for linearly polarized, dual-frequency microstrip antenna at $\mathrm{S}$ - and X-bands has been presented $^{20}$. Reference 21 elaborates different configurations of microstrip antenna array for phased array radar and beam forming algorithms. CSRR technique is used in ref. 22 for the enhancement of gain and bandwidth. CSRR technique is also used for the antenna miniaturization as explained in ref. 23. Various antenna parameter improvement techniques are discussed in ref. 24.

\section{Results and discussion}

This study presents good results regarding bandwidth compared to the impedance bandwidth of an earlier 

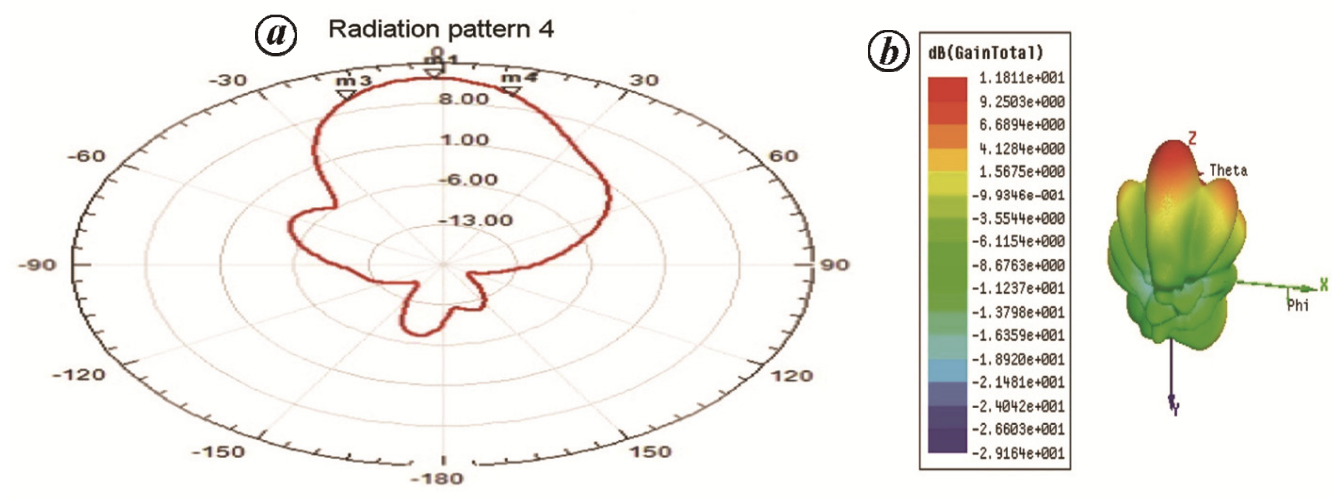

Figure 3. $\boldsymbol{a}$, Two-dimensional radiation pattern. $\boldsymbol{b}$, Three-dimensional radiation pattern.

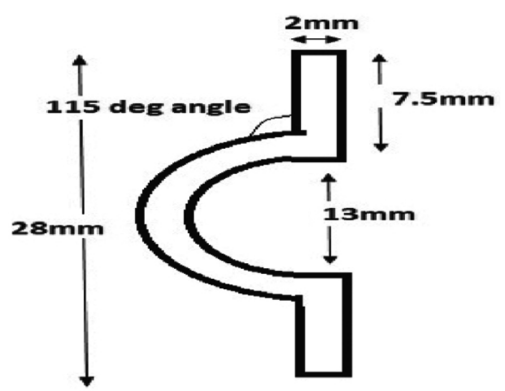

Figure 4. Omega-shaped DGS.

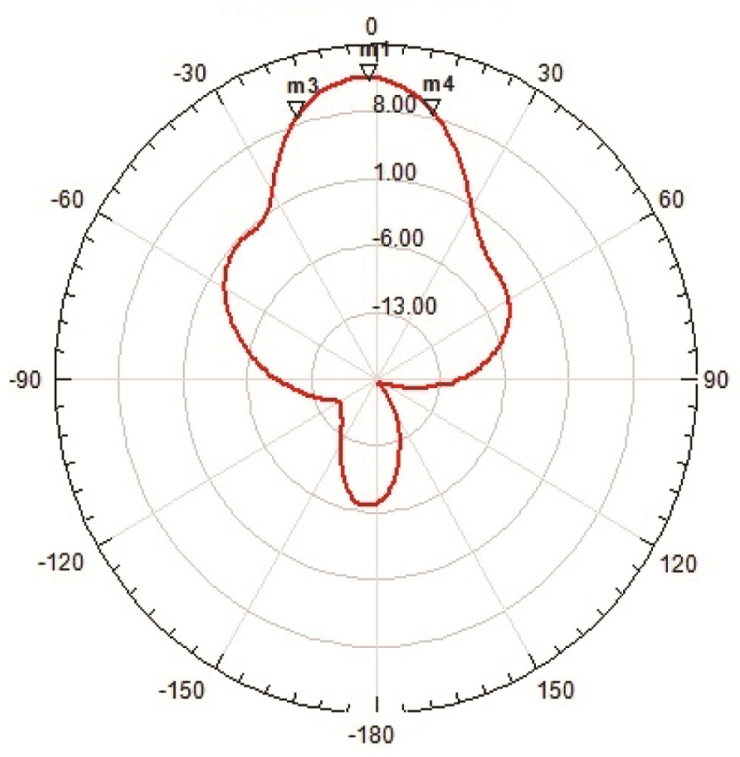

Figure 5. 2D radiation pattern.

study $^{25}$. A $4 \times 4$ antenna array with distinct element size has been analysed at 3.5 and $5 \mathrm{GHz}$. The results of earlier studies $^{20,25-27}$ are compared with those of the present study. It is observed that results of this study are good in the context of bandwidth, cross-polarization and gain. They ${ }^{25}$ got a bandwidth of $20.4 \%$ for the S-band. We obtained a bandwidth of $77.12 \%$ for the S-band and $46.56 \%$

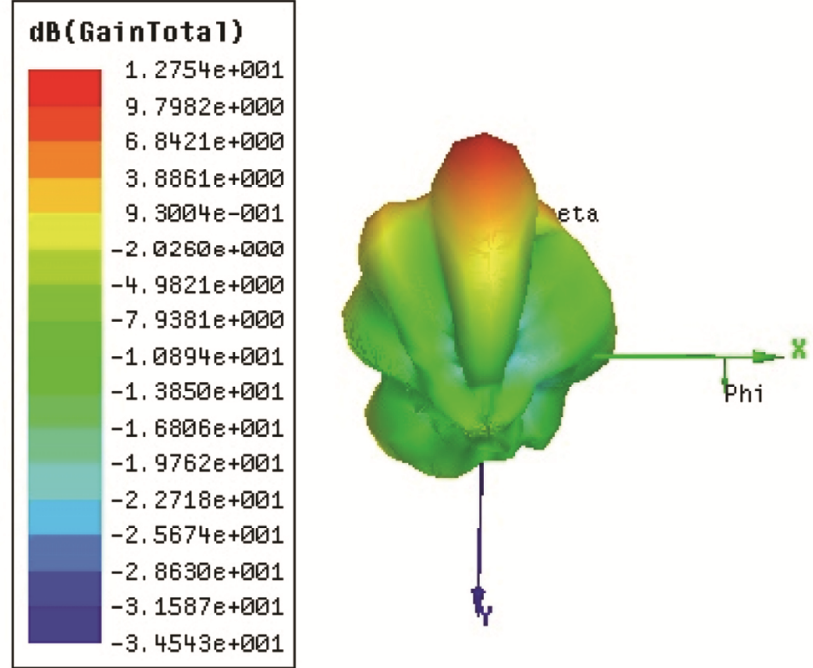

Figure 6. 3D gain radiation pattern.

for the C-band. Side lobe level was up to $-20.11 \mathrm{~dB}$. They ${ }^{25}$ have utilized the ground plane for S-band. In this article, the vertical length of DGS is $28 \mathrm{~mm}$ and width is $2 \mathrm{~mm}$. A $13 \mathrm{~mm}$ semicircle opening is chosen. The angle between the semicircle and vertical length is $115^{\circ}$. The amount of current diversion depends on the depth of angle. More the angle, more will be the bandwidth. The $13 \mathrm{~mm}$ opening is selected here. If we increase the opening dimension, it will change the shape, i.e. it will become more circular. Figure 6 shows the 2D radiation gain pattern. Beamwidth gets reduced with DGS. It is observed that after DGS, the beamwidth reduces by $10^{\circ}$. It is $30^{\circ}$. Side lobe level is also reduced up to $20.11 \mathrm{~dB}$ with DGS. Figure 7 shows the co-cross polarized plot. It is reduced up to $-16.5 \mathrm{~dB}$. Polarization is mainly classified into two types, viz. co-polarization and cross-polarization. The latter quantifies how much power is radiated in unwanted directions. So it should be as low as possible. $\mathrm{X}$ pol is a loss of signal at the receiver end. It is a noise signal as far as detection is concerned. Co pol is the radiation in the desired direction. The cross polar is 
Table 1. Comparison of antenna array with and without DGS

\begin{tabular}{|c|c|c|c|c|c|c|c|c|c|}
\hline Results & $\begin{array}{c}\text { Frequency } \\
\quad(\mathrm{GHz})\end{array}$ & $\begin{array}{c}\text { Return } \\
\text { loss (dB) }\end{array}$ & VSWR & $\begin{array}{c}\text { BW } \\
(\mathrm{MHz})\end{array}$ & $\begin{array}{c}\text { Directivity } \\
\text { (dB) }\end{array}$ & $\begin{array}{l}\text { Gain } \\
(\mathrm{dB})\end{array}$ & $\begin{array}{c}\text { Beam } \\
\text { width (deg) }\end{array}$ & $\begin{array}{l}\text { SLL } \\
(\mathrm{dB})\end{array}$ & $\begin{array}{c}\text { Cross } \\
\text { polar }(\mathrm{dB})\end{array}$ \\
\hline Without DGS & $\begin{array}{l}2.42 \\
5.87\end{array}$ & $\begin{array}{l}-21.16 \\
-16.60\end{array}$ & $\begin{array}{l}1.21 \\
1.34\end{array}$ & $\begin{array}{l}1100 \\
2400\end{array}$ & 12.42 & 11.8 & 40.2 & -17.5 & 3.7 \\
\hline With DGS & $\begin{array}{l}2.45 \\
5.87\end{array}$ & $\begin{array}{l}-20.09 \\
-14.94\end{array}$ & $\begin{array}{l}1.22 \\
1.43\end{array}$ & $\begin{array}{l}1860 \\
2500\end{array}$ & 13.3 & 12.7 & 30.0 & -20.11 & -16.5 \\
\hline
\end{tabular}
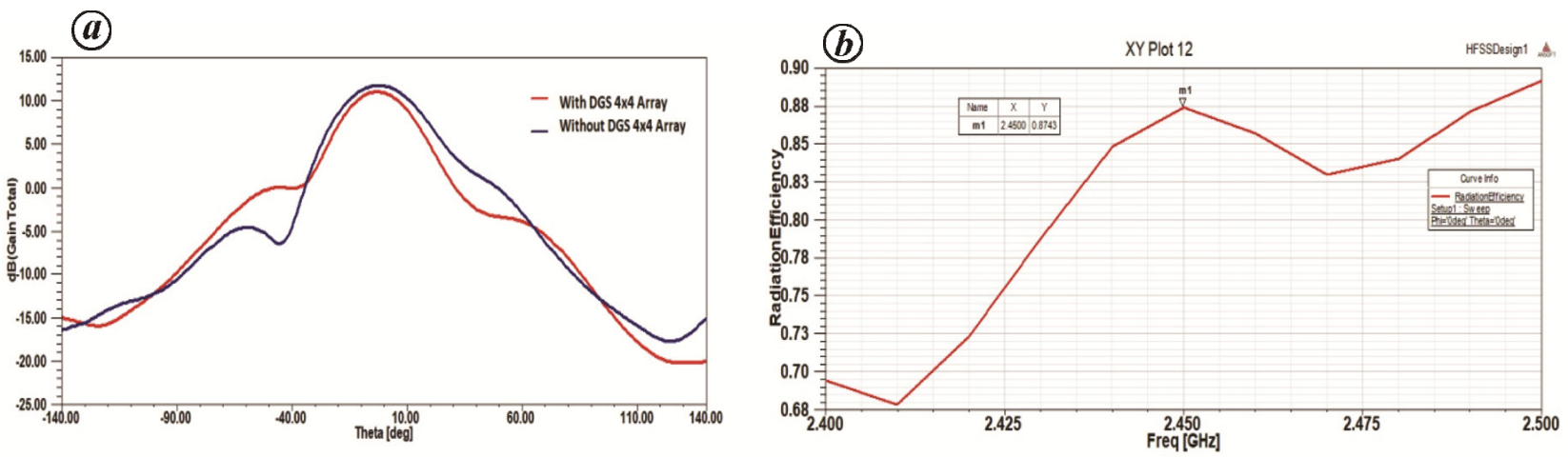

Figure 7. $\boldsymbol{a}$, Side lobe level plot. $\boldsymbol{b}$, Frequency versus efficiency plot.

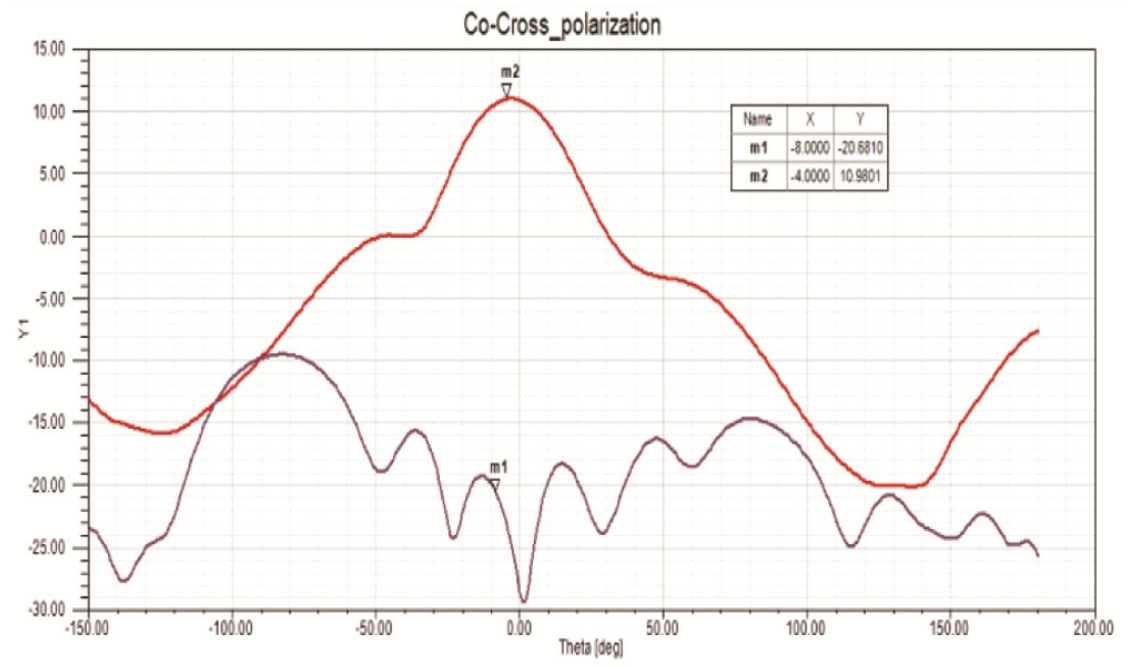

Figure 8. Co-cross polarization.

basically considered as a dissipation in antenna radiation. Co-polarization is defined as the polarization in the desired direction that the antenna was supposed to radiate, while cross pol is defined as its orthogonal pair. A purely polarized antenna will have low cross-polarized radiation. Figure $7 b$ shows frequency versus efficiency plot, it is up to $88 \%$. Figure 9 shows the E-plane radiation pattern. It is observed that cross-polarization (blue colour) level is below $-22 \mathrm{~dB}$ and co-polarization level (red colour) is around $12 \mathrm{~dB}$. It is observed that in planar array, crosspolarization has more impact. It is required that the crosspolarization level must be low. In this design, the level is tolerable. Table 1 shows a comparison between the antenna array with and without DGS. From Table 2, it is observed that bandwidth improved by inserting DGS into the ground plane. Gain and directivity are also enhanced. Cross-polarization is reduced by a great extent.

\section{Conclusion}

A novel configuration for a dual-band hexagonal array antenna having wideband performance is proposed in this study. A $4 \times 4$ hexagonal antenna array with DGS at WLAN $2.4 \mathrm{GHz}$ and $\mathrm{C}$-band $5.8 \mathrm{GHz}$ is used to achieve 


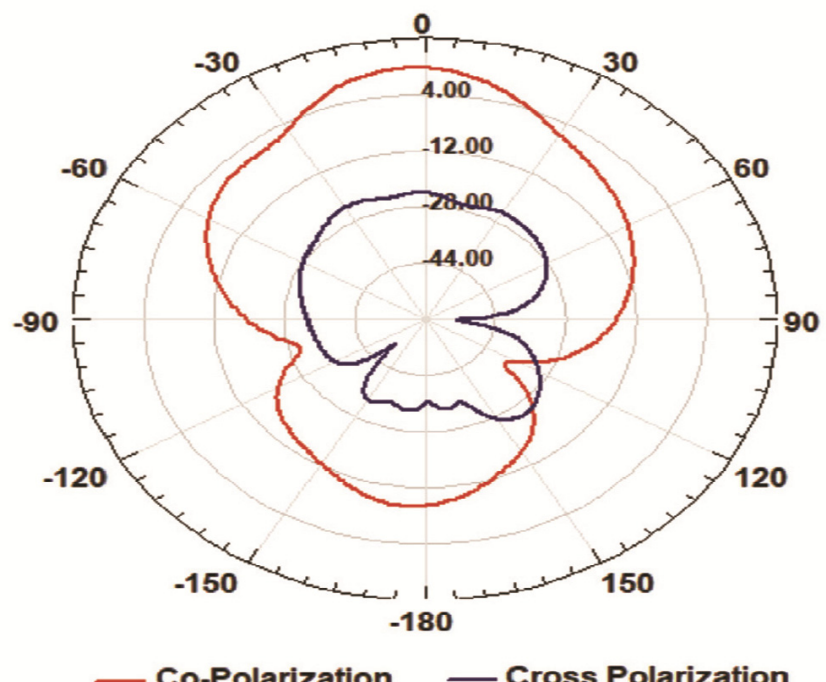

Figure 9. E-plane radiation pattern at $2.4 \mathrm{GHz}$.

Table 2. Comparison of reference paper results ${ }^{19,20,25,26}$ and proposed antenna array results

\begin{tabular}{|c|c|c|c|c|c|}
\hline Reference & Frequency $(\mathrm{GHz})$ & Bandwidth (MHz) & Gain $(\mathrm{dB})$ & Material & Overall size $(\mathrm{mm})$ \\
\hline Yin Yue and Jianyi Zhou & 2.4 & $48.96 \mathrm{MHz}$ & 7.84 & $\begin{array}{l}\varepsilon_{\mathrm{r}}=2.55 \\
\text { substrate } \mathrm{ht}=1 \mathrm{~mm}\end{array}$ & - \\
\hline $\begin{array}{l}\text { Zaakri Safa and } \\
\text { Zenkouar Lahbib }\end{array}$ & 12 and 18 & $\begin{array}{l}\text { Narrowband around } \\
200 \mathrm{MHz}\end{array}$ & 6.49 low & $\begin{array}{l}\text { ArlonDiClad } \\
880 \text { of } \varepsilon_{\mathrm{r}}=2.2\end{array}$ & - \\
\hline $\begin{array}{l}\text { Pratigya Mathur and } \\
\text { Girish Kumar }\end{array}$ & 2.5 and 8 & $13 \%, 6.2 \%$ & $\begin{array}{l}7.5 \mathrm{dBi} \\
10.5 \mathrm{dBi}\end{array}$ & RT 5880 & - \\
\hline $\begin{array}{l}\text { R. Rajeswari }{ }^{1} \text {, } \\
\text { P. Sudharshini }{ }^{2} \text { and } \\
\text { S. V. Vidhya Harini }{ }^{3}\end{array}$ & 3.1 and 4.5 & $\begin{array}{l}\text { Narrowband } \\
\text { around } 150 \mathrm{MHz}\end{array}$ & 9.95 high & $\mathrm{FR} 4\left(\varepsilon_{\mathrm{r}}=4.6\right)$ & $300 \times 340 \mathrm{~mm}^{2}$ \\
\hline $\begin{array}{l}\text { Proposed hexagonal } \\
\text { dual band }\end{array}$ & 2.4 and 5.8 & $\begin{array}{l}\text { Wideband } 1860 \mathrm{MHz} \text {, } \\
2500 \mathrm{MHz}\end{array}$ & 12.70 high & $\mathrm{FR} 4\left(\varepsilon_{\mathrm{r}}=4.6\right)$ & $240 \times 290 \mathrm{~mm}^{2}$ \\
\hline
\end{tabular}

high gain. This configuration uses omega-shaped DGS to reduced size and enhanced bandwidth of the array antenna. It achieves bandwidth of $1860 \mathrm{MHz}$ at WLAN band and $2500 \mathrm{MHz}$ at C-band without any interference between the two bands. We have demonstrated $12 \mathrm{~dB}$ improvement in the isolation between co-pol and cross-pol radiations using omega-shaped DGS structure. It is found that the efficiency of this design is $88 \%$. The hexagonal array with corporate feed microstrip antenna characteristics with and without DGS has been studied using CST software. This antenna array is applicable for WLAN and radar systems.

1. Moltz, K. F., Phased array radar system. IET J. Radio Electron. Eng., 1964, 331-339.

2. Dewantari, A., Kim, J., Se-Yeon, Kim, S. and Ka, Min-Ho, Gain and SLL Improvement of $\mathrm{W}$ band microstrip array antenna with CSRR for radar application. Electron. Lett., 2017, 53(11).
3. Alibakshi-Kenari, M., Naser-Moghadasi, M., Sadeghzadeh, R. A., Bal S. Virdee and Limitl, E., Bandwidth extension of planar antennas using embedded slits for reliable multiband RF communication. Int. J. Electron. Commun., 2016, 70(7), 910-919.

4. Liu, Y.-Q., Liang, J.-G. and Wang, Y.-W., Design of a novel BWenhanced double double slot TSA and analysis according to the microwave network theory. Int. J. Electron. Commun., 2017, 80, 186-192.

5. Hideo Lizuka, Kunio Sakakibara, Toshiaki Watanabe, Kazuo Sato and Kunitoshi Nishikawa, Millimeter-wave microstrip array antenna with high efficiency for automotive radar systems, R\&D Review of Toyota CRDL, 2002, vol. 37, No. 2, pp. 7-12.

6. Bayderkhani, R. and Hassani, H. R., Wideband low sidelobe slot antenna fed by series-fed printed array. IEEE Trans. Antenna Propag., 2010, vol. 58(12), pp. 3898-3904.

7. Jung, Y. B., Yeom, I. and Jung, C. W., Center-fed series array antenna for $\mathrm{K} / \mathrm{Ka}$ band electromagnetic sensors. IET Microwave Antenna Propagation, 2012, vol. 6, pp. 588-593.

8. Mathur, P., Kumar, G., Mishra, P. K. and Verma, Y. K., Large gain linear series fed microstrip antenna arrays at $\mathrm{Ka}$ and $\mathrm{C}$ bands. IEEE International Symposium, 2015, pp. 1872-1873. 
9. Kuo, F. Y. and Hwang, R.-B., High isolation X-band marine radar antenna design. IEEE Transaction on Antennas and Propagation, 2014, vol. 62, no. 5 .

10. Bisognin, A. et al., Differential feeding technique for $\mathrm{mm}$ wave series fed antenna array. Electron. Lett., 2013, 49(15).

11. Topak, E., Hasch, J., Wagner, C. and Zwick, T., A novel mm-wave dual fed phased array for beam steering. IEEE Trans. Microwave Theory, 2013, 61(8).

12. Acharjee, J., Mandal, K., Mandal, S. K. and Sarkar, P., Mutual coupling reduction between microstrip patch antennas by using a string of H-shaped DGS. IEEE Conference on Microelectronics, Computing and Communication, 2016.

13. Sung, Y. J., Kim, M. and Kim, Y. S., Harmonics reduction with DGS for microstrip patch antenna. IEEE Antennas Wireless Propag. Lett., 2003, 2.

14. Hoti, K., Sabbar, N., Bdellah Hajjaji, A. and Asselman, H., Novel multiband patch antenna array for satellite application. Proc. Eng., 2017.

15. Mishra, R., Kuchhal, P. and Kumar, A., Effect of height of substrate and width of patch on the performance characteristics of microstrip antenna. Int. J. Electr. Comput. Eng., 2015, 1441-1445.

16. Ali-Sheikh, Shen, Z., Design of wideband bandstop frequencyselective surfaces using stacked parallel strip line arrays, IEEE Transaction on Antenna and Propagation.

17. Yang, F. and Rahmat Samii, Y., Electromagnetic Band Gap Structure in Antenna Engineering, Cambridge University Press, USA, 2009

18. Guha, D., Biswas, M. and Yahia M. M. Antar, Microstrip patch antenna with defected ground structure for cross polarization suppression. IEEE Antenna Wireless Propag. Lett., 2005.

19. Pandhare, R. and Zade, P. L., Miniaturized microstrip antenna array using defected ground structure with enhanced performance. Eng. Sci. Technol., 2016, 19(3), 1360-1367.
20. Mathur, P. and Kumar, G., Large grain linear series - Fed microstrip Antenna Arrays at $\mathrm{Ka}$ and $\mathrm{C}$ bands. Prog. Electromagn. Res. Lett., 2017, 71, 15-22.

21. Wagh, K. H., Microstrip array antenna and beamforming algorithm for phased array radar. Int. J. Adv. Res. Educ. Technol., 2015, 148-151.

22. Wagh, K. H. and Shriramwar, S. S., Gain and bandwidth enhancement of array antenna for $\mathrm{S}$ and $\mathrm{C}$ band application. Int. J. Adv. Sci. Technol., 2018, 1239-1241.

23. Wagh, K. H. and Shriramwar, S. S., Miniaturization and gain enhancement of array antenna for dual band radar system. IEEE Indian Conference on Antenna and Propagation, Hyderabad, 2018.

24. Wagh, K. H. and Shriramwar, S. S., Design of microstrip antenna array for radar application: a review. Int. J. Mod. Electron. Commun. Eng., 2018, 181-186.

25. Yue, Y. and Zhou, J., A wideband dual polarized antenna array for multifunction radar. In IEEE 5th Asia-Pacific Conference on Antenna and Propagation. Nanjing, China, 2016.

26. Safa, Z. and Lahbib, Z., Conception of Bi-band rectangular microstrip array antenna. J. Microwaves, 2013, 12(1)

27. Rajeshwari, R., Sudharshini, P. and Vidhya Harini, S. V., Design of dual band dissimilar patch size array antenna for wireless applications. Int. J. Inf. Sci. Tech., 2014, 31-38.

ACKNOWLEDGEMENTS. We thank the Society for Applied Microwave Electronics Engineering and Research, IIT Bombay Campus, Powai, Mumbai for providing laboratory facilities to carry out this work. We also thank LRDE (DRDO), Bengaluru for their support.

Received 19 September 2018; revised accepted 7 September 2019

doi: $10.18520 / \mathrm{cs} / \mathrm{v} 118 / \mathrm{i} 2 / 249-254$ 